\title{
Estimates of prevalence of anti-SARS-CoV-2 antibodies among blood donors in eight provinces of South Africa in November 2021
}

\section{Russel Cable}

Western Cape Blood Service

Charl Coleman

South African National Blood Service

Tanya Glatt

South African National Blood Service https://orcid.org/0000-0002-5458-5791

\section{Eduard Grebe}

Vitalant Research Institute https://orcid.org/0000-0001-7046-7245

\section{Laurette Mhlanga}

Stellenbosch University https://orcid.org/0000-0002-7805-4231

\section{Cynthia Nyano}

South African National Blood Service

\section{Nadia Pieterson}

Western Cape Blood Service

\section{Ronel Swanevelder}

South African National Blood Service

\section{Avril Swarts}

South African National Blood Service

\section{Wendy Sykes}

South African National Blood Service

\section{Karin van den Berg}

South African National Blood Service https://orcid.org/0000-0001-9805-8013

Marion Vermeulen ( $\nabla$ marion.vermeulen@sanbs.org.za )

South African National Blood Service https://orcid.org/0000-0003-4383-4526

\section{Alex Welte}

Stellenbosch University https://orcid.org/0000-0001-7139-7509

\section{Short Report}

Keywords: COVID-19, seroprevalence, anti-SARS-CoV-2 antibodies, blood donors, South Africa 
Posted Date: February 15th, 2022

DOI: https://doi.org/10.21203/rs.3.rs-1359658/v1

License: (c) (i) This work is licensed under a Creative Commons Attribution 4.0 International License. Read Full License 


\title{
Estimates of prevalence of anti-SARS-CoV-2 antibodies
}

\section{among blood donors in eight provinces of South Africa in November 2021}

\section{An interim analysis from an ongoing national study}

14 February 2022

Russel Cable 2

Charl Coleman 1

Tanya Glatt 1

Eduard Grebe 3,4

Laurette Mhlanga 3

Cynthia Nyoni 1

Nadia Pieterson 2

Ronel Swanevelder 1

Avril Swarts 1

Wendy Sykes 1

Karin van den Berg 1

Marion Vermeulen 1

Alex Welte 3

\section{Affiliations:}

1. South African National Blood Service

2. Western Cape Blood Service

3. DSI-NRF Centre of Excellence in Epidemiological Modelling and Analysis (SACEMA), Stellenbosch University

4. Vitalant Research Institute

\begin{abstract}
In line with previous instalments of analysis from this ongoing study to monitor 'Covid Seroprevalence' among blood donors in South Africa, we report on analysis of 3395 samples obtained from 8 to 12 November 2021 in all provinces of South Africa except the Western Cape. As in our previous analyses, we see no evidence of age and sex dependence of prevalence, but substantial variation by province, and by race within each province, from which we generated provincial total point estimates (EC-74\%; FS-75\%; GP-68\%; ZN-73\%; LP-66; MP-73\%; NC-63\%; NW$81 \%$ ) and a 'South Africa minus Western Cape' national prevalence estimate of $71 \%(95 \% \mathrm{Cl} 69-74 \%)$. We note that sample collection occurred just before the omicron variant driven wave in South Africa, but otherwise present these results without significant interpretation.
\end{abstract}




\section{Introduction}

We have previously published estimates of the prevalence of anti-SARS-CoV-2 antibodies among blood donors in South Africa, based on specimens collected from January to May 2021 [1,2], as well as estimates of fatality rates, based on these prevalence estimates and publicly available excess deaths estimates [3].

While the interpretation of seroprevalence is increasingly complicated by vaccination coverage and multiple infections of individuals, we understand that seroprevalence is still relevant from the point of view of understanding aspects of transmission and collective immunity that are relevant to ongoing adjustment of anti-transmission measures, policies, and regulation.

\section{Methods}

Anticipating that a fourth wave late in 2021 was inevitable (though there was no knowledge of the omicron variant at the time of planning), 3395 specimens were randomly collected from consenting donors from all provinces except the Western Cape (which has its own separate blood service) presenting to donate blood to the South African National Blood Service (SANBS) from 8 to 12 November 2021. This was carried out in accordance with previous arrangements and practices underlying our previous rounds of sampling [1,2], as approved by the SANBS Human Research Ethics Committee (HREC).

For analysis, serology data was linked to basic donor demographic information (age, sex and race) but not to any other underlying data potentially available from the SANBS donor database (donation history, specific locale of donation/residence, donor identifiers etc).

Samples were tested for the presence of antibodies to SARS-CoV-2 nucleocapsid proteins, using the Roche Elecsys platform. These antibodies are typically developed in response to natural infection, but not in response to any vaccine currently available in South Africa. While there is some waning of antibodies, in this context we expect about 95 percent of donors who ever developed antibodies to have detectable levels at the time of testing [4] while a small proportion (we estimate in the range of 5-10 percent) of individuals who experience infection never develop detectable antibodies. [5]

\section{Results}

Figure 1 shows the distribution of specimens by age group, race, sex and province. We found no statistically significant dependence of seroprevalence on either age or sex. However, unsurprisingly, there were statistically and epidemiologically significant differences between provinces, and among race groups in each province. Hence:

- We report primary results by every combination of province and racial group (Figure 1).

- From these, we generated a race-weighted seroprevalence for each province (Figure 2).

- From these provincial estimates, we generated a 'national' (minus Western Cape) estimate by weighting according to provincial population sizes (Table 1 ). 


\section{Discussion}

We note well known caveats about representativeness of donors, and also that at this stage of the epidemic there is an increasing incidence of reinfection. In this study we did not detect antibodies developed due to vaccination.

For the present purposes, we do not offer any substantial interpretation of these results, but trust that they will be of interest and use to modellers, policy makers and others.

More resource intensive surveillance, notably defined by:

- More frequent rounds of sampling

- Multi-assay testing algorithms to distinguish vaccine induced antibodies from antibodies produced by natural infection

- Sequencing

would potentially be significantly more informative.

\section{Acknowledgements}

The authors would like to thank the community of South African blood donors, whose voluntary provision of blood daily saves lives, and whose participation in studies enables highly efficient timely research. We also thank many colleagues in the blood services, for their efforts to execute this research in addition to their daily responsibilities, and colleagues at the National Institute of Communicable Diseases, for ongoing discussions which inform the data collection and analysis.

Funding for the operational activities was provided by the South African National Blood Service and in part supported by the South African Medical Research Council with funds received from the Department of Science and Innovation. The time of investigators in the blood services is supported by the blood services. Karin van den Berg and Marion Vermeulen are also supported by the NIH Fogarty International Center training grant 1D43-TW010345. Alex Welte and Laurette Mhlanga are supported by a Centre of Excellence grant from the South African Department of Science and Innovation via the National Research Foundation (Any opinion, finding, and conclusion or recommendation expressed in this material is that of the authors, and the NRF does not accept any liability in this regard). Eduard Grebe is supported by internal funding from Vitalant Research Institute, San Francisco.

\section{Conflicts of Interest}

The Authors have no conflicts of interest to declare 
Figure 1: Age distribution of specimens included in the present analysis, further decomposed by race and province.

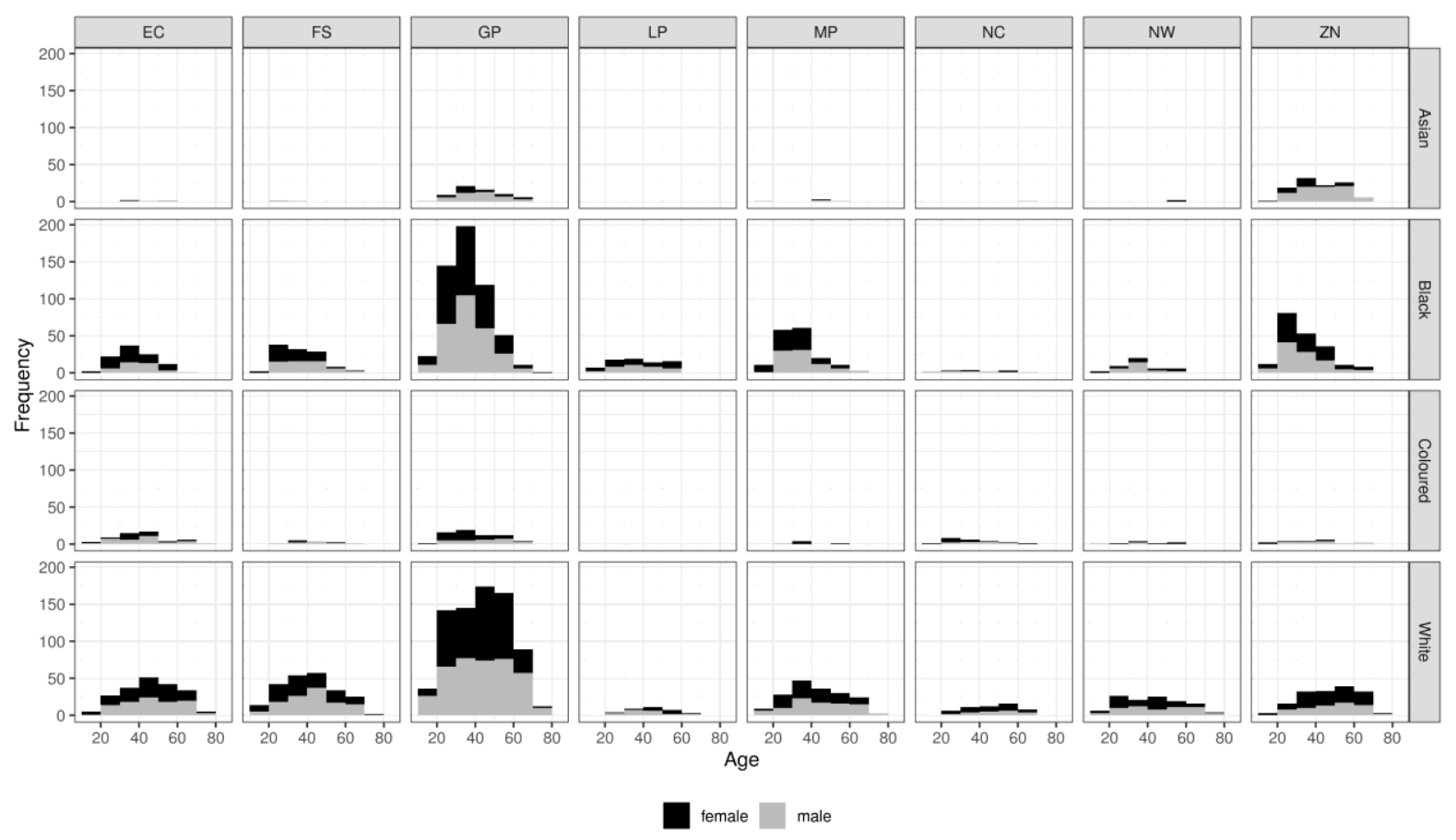


Figure 2: Seroprevalence estimates, for each sampled province, by race, and a race weighted provincial total.

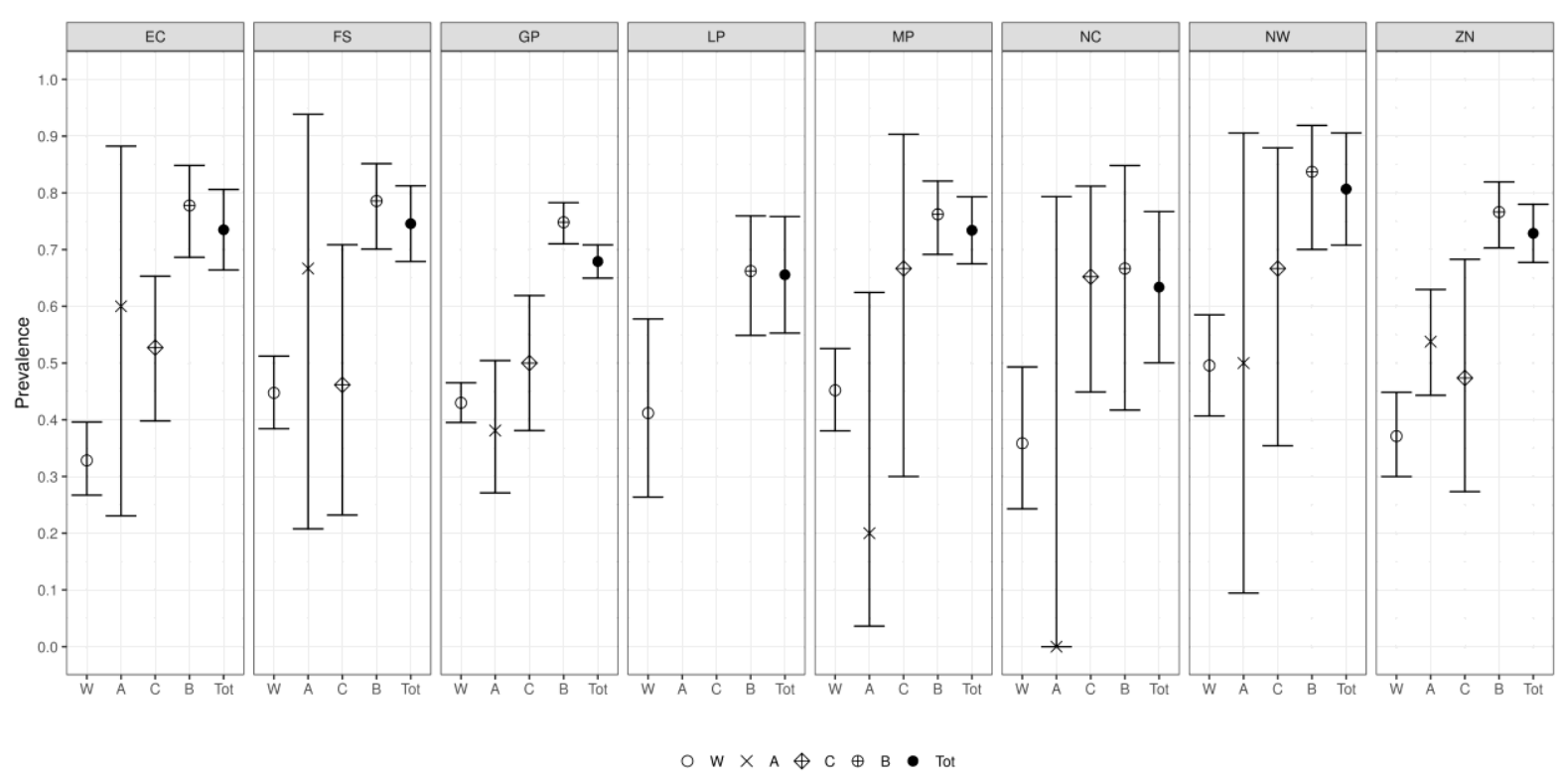


Table 1: The numerical provincial race-weighted seroprevalence values underlying figure 2

\begin{tabular}{|l|c|c|c|}
\hline \multicolumn{1}{|c|}{ Province } & $\begin{array}{c}\text { Point Estimate } \\
\text { (\%) }\end{array}$ & $\begin{array}{c}\text { 95\% Confidence } \\
\text { Interval } \\
\text { Lower bound (\%) }\end{array}$ & $\begin{array}{c}\text { 95\% Confidence } \\
\text { Interval } \\
\text { Upper bound (\%) }\end{array}$ \\
\hline Eastern Cape & 73.5 & 66.0 & 81.0 \\
\hline Free state & 74.6 & 67.5 & 81.6 \\
\hline Gauteng & 67.9 & 64.9 & 70.9 \\
\hline Limpopo & 65.6 & 54.6 & 76.5 \\
\hline Mpumalanga & 73.4 & 67.2 & 79.6 \\
\hline Northern cape & 63.4 & 48.1 & 78.7 \\
\hline North West & 80.7 & 69.9 & 91.5 \\
\hline KwaZulu Natal & 72.9 & 67.5 & 78.2 \\
\hline 8 Province Mean & $\mathbf{7 1 . 1}$ & $\mathbf{6 8 . 8}$ & $\mathbf{7 3 . 5}$ \\
\hline
\end{tabular}




\section{References}

1. W Sykes, L Mhlanga, R Swanevelder, TN Glatt, E Grebe, C Coleman, N Pieterson, R Cable, A Welte, $\mathrm{K}$ van den Berg, $\mathrm{M}$ Vermeulen Prevalence of anti-SARS-CoV-2 antibodies among blood donors in Northern Cape, KwaZulu-Natal, Eastern Cape, and Free State provinces of South Africa in January 2021 Preprint DOI:10.21203/rs.3.rs-233375/v1

2. M Vermeulen, L Mhlanga, W Sykes, C Coleman, N Pieterson, R Cable, R Swanevelder, TN Glatt, E Grebe, A Welte, $\mathrm{K}$ van den Berg; Prevalence of anti-SARS-CoV-2 antibodies among blood donors in South Africa during the period January-May 2021. Preprint DOI:10.21203/rs.3.rs-690372/v2

3. L Mhlanga, M Vermeulen, E Grebe, A Welte SARS CoV $\mathbf{2}$ Infection Fatality Rate Estimates for South Africa Preprint DOI: 10.21203/rs.3.rs-707813/v2

4. M Stone, E Grebe, H Sulaeman, C Di Germanio, H Dave, K Kelly, B Biggerstaff, B O. Crews, N Tran, KR Jerome, TN Denny, B Hogema, M Destree, JM Jones, N Thornburg, G Simmons, M Krajden, S Kleinman, LJ Dumont, MP Busch Evaluation of commercially available highthroughput SARS-CoV-2 serological assays for serosurveillance and related applications Preprint DOI:https://doi.org/10.1101/2021.09.04.21262414

5. TN Glatt, C Hilton, C Nyoni, A Swarts, R Swanevelder, J Cowley, C Mmenu, T Moyo-Gwete , PL Moore, M Kutama, J Jaza, I Phayane, T Brits, J Koekemoer, U Jentsch, D Nelson, K van den Berg, M Vermeulen Rapid and Successful Implementation of a COVID-19 Convalescent Plasma Programme-The South African Experience Viruses 2021, 13, 2050. https://doi.org/10.3390/v13102050 